\title{
Serotonergic Psychedelics in Neural Plasticity
}

\author{
Kacper Lukasiewicz, Jacob J. Baker, Yi Zuo and Ju Lu* \\ Department of Molecular, Cell and Developmental Biology, University of California, Santa Cruz, Santa Cruz, CA, United States
}

Psychedelics, compounds that can induce dramatic changes in conscious experience, have been used by humans for centuries. Recent studies have shown that certain psychedelics can induce neural plasticity by promoting neurite growth and synapse formation. In this review, we focus on the role of classical serotonergic psychedelics in neural plasticity and discuss its implication for their therapeutic potentials.

Keywords: psychedelics, synapse, neural plasticity, 5- $\mathrm{HT}_{2 \mathrm{~A}}$, psychoplastogen, psychiatric disorders

\section{INTRODUCTION}

To fathom Hell or soar angelic, just take a pinch of psychedelic.

-Huxley and Osmond, 2018.

The term "psychedelic" was coined by the psychiatrist Humphry Osmond in 1956 in correspondence with the renowned author Aldous Huxley to remarket a class of compounds that induce profound changes in consciousness (Huxley and Osmond, 2018). Combining two

OPEN ACCESS

Edited by:

Yang Yang,

ShanghaiTech University, China

Reviewed by:

Chiayu Chiu,

Universidad de Valparaíso, Chile

Mary M. Torregrossa,

University of Pittsburgh, United States

*Correspondence:

Ju Lu

jlu39@ucsc.edu

Specialty section:

This article was submitted to Neuroplasticity and Development,

a section of the journal

Frontiers in Molecular Neuroscience

Received: 27 July 2021

Accepted: 13 September 2021

Published: 12 October 2021

Citation:

Lukasiewicz K, Baker JJ, Zuo Y and Lu J (2021) Serotonergic Psychedelics in Neural Plasticity.

Front. Mol. Neurosci. 14:748359. doi: 10.3389/fnmol.2021.748359
Greek roots, psyche (soul, mind) and deloun (to manifest), the word means "mind-manifesting." Previously, these compounds had been called "psychotomimetics" due to their ability to induce a transient, schizophrenia-like episode in healthy people (Gerard, 1956). Over the years, researchers have referred to this class of compounds variously as entheogens ("possessed by a god") (Ruck et al., 1979), empathogens ("empathy-generating”) (Nichols et al., 1993), entactogens ("touching within") (Nichols, 1986), and hallucinogens (Nichols, 2004), reflecting a constantly evolving perspective on their physiological and cultural impact.

The most recent term "psychoplastogen" emphasizes these drugs as catalysts for neuroplasticity in the brain (Olson, 2018). There is growing evidence that psychedelics promote the structural and functional plasticity of synapses (Ly et al., 2018; Inserra et al., 2021a; Kadriu et al., 2021), sites where neurons connect and communicate with each other. Interestingly, some structurally similar compounds share this feature but lack hallucinogenic effects (Cameron et al., 2021; Dong et al., 2021). As changes in synaptic circuits are widely believed to underlie learning and memory (Holtmaat and Svoboda, 2009), and numerous psychiatric disorders exhibit deficits in neuroplasticity (Goto et al., 2010; Forrest et al., 2018), psychedelics have attracted significant research interest in their molecular and cellular mechanisms of action (Inserra et al., 2021a; Kadriu et al., 2021), as well as in their therapeutic potential for psychiatric disorders such as addiction, depression, and anxiety (Carhart-Harris and Goodwin, 2017; Rucker et al., 2018; Dos Santos and Hallak, 2020).

Classical psychedelics fall into three main groups: tryptamines, ergolines, and phenethylamines (Nichols, 2016). They have diverse origins. For example, N, N-dimethyltryptamine (DMT) naturally occurs in mammalian brains (Saavedra and Axelrod, 1972); psilocybin is extracted from Psilocybe mushrooms (Hofmann et al., 1958) and mescaline from the peyote cactus Lophophora williamsii (Heffter, 1894); lysergic acid diethylamide (LSD) and 2,5-dimethoxy-4iodoamphetamine (DOI) are semi-synthetic. They preferentially bind to the serotonin $2 \mathrm{~A}\left(5-\mathrm{HT}_{2 \mathrm{~A}}\right)$ receptor (Nichols, 2016), and the affinity is strongly correlated with the hallucinogenic effect 
(Glennon et al., 1984). Administration of ketanserin, a 5$\mathrm{HT}_{2 \mathrm{~A}}$ receptor antagonist, blocks the hallucinogenic effect of the classical psychedelic psilocybin (Vollenweider et al., 1998). Moreover, in 5- $\mathrm{HT}_{2 \mathrm{~A}}$ knock-out (KO) mice, psychedelics do not produce the head-twitch response (high-frequency paroxysmal head rotation), a rodent proxy of hallucinatory behavior (Gonzalez-Maeso et al., 2007). A recent human study also reveals that the subjective intensity of psychedelic experience is correlated with $5-\mathrm{HT}_{2 \mathrm{~A}}$ receptor occupancy in the brain (Madsen et al., 2019). Therefore, signaling induced by $5-\mathrm{HT}_{2 \mathrm{~A}}$ receptor activation is likely necessary for psychedelics to cause hallucinations, even though many psychedelics bind to other receptors (e.g., 5- $\mathrm{HT}_{1 \mathrm{~A}}$, other $5-\mathrm{HT}_{2}$, and dopamine receptors) as well (Cumming et al., 2021). Since serotonin regulates mood, stress response, appetite, and reward processing (Berger et al., 2009), compounds with an affinity for 5-HT receptors may affect all these brain functions. As the pharmacology and downstream signaling pathways of psychedelics have been covered recently by excellent reviews (Lopez-Gimenez and Gonzalez-Maeso, 2018; Cumming et al., 2021; Kadriu et al., 2021), we will instead focus on the role of classical psychedelics in neural plasticity.

\section{CLASSICAL PSYCHEDELICS AND THEIR EFFECTS ON NEUROPLASTICITY AND NEURAL CIRCUITS}

\section{$\mathrm{N}, \mathrm{N}$-Dimethyltryptamine (DMT) and Its Derivatives}

DMT is an active ingredient in ayahuasca ("vine of the soul" in the Quechua language), a hallucinogenic drink consumed in shamanic rituals in South America. DMT can promote neuroplasticity both in vitro and in vivo. In cultured rat cortical neurons, DMT treatment for $24 \mathrm{~h}$ promotes the growth of neurites (axonal and dendritic processes emanating from the neuronal cell body), increasing their number, length, and complexity. The treatment also increases the density of dendritic spines (tiny protrusions from dendrites that are the postsynaptic sites of synapses). The increased spinogenesis is associated with synaptogenesis, as evidenced by an increase in the puncta density of VGLUT1, a presynaptic vesicular glutamate transporter. Likewise, a single high dose of DMT (10 mg/kg) increases synaptic density on pyramidal neurons in the prefrontal cortex (PFC) of adult rats. The structural changes are accompanied by functional changes, as shown by an increase in the frequency and amplitude of spontaneous excitatory postsynaptic currents (EPSCs) recorded ex vivo (Ly et al., 2018). In contrast, chronic, intermittent administration of a low dose of DMT $(1 \mathrm{mg} / \mathrm{kg})$ decreases PFC dendritic spine density in female, but not male, rats (Cameron et al., 2019). These findings suggest that DMT's psychoplastogenic effect is dose- and sex-dependent.

The molecular mechanisms underlying the neuroplastic effects of DMT are complicated. It likely involves $5-\mathrm{HT}_{2 \mathrm{~A}}$ signaling, as it can be blocked by co-treatment with ketanserin. Co-treatment with ANA-12, a selective antagonist of TrkB (tyrosine receptor kinase B), or rapamycin, an inhibitor of mTOR (mechanistic target of rapamycin), also blocks it, implicating
TrkB and mTOR signaling in DMT-induced neuroplasticity as well (Ly et al., 2018). Furthermore, DMT is an agonist for the sigma-1 receptor, a chaperone protein at the endoplasmic reticulum that modulates calcium signaling (Fontanilla et al., 2009). As sigma-1 receptors can regulate voltage-gated ion channels and synaptic transmission (Kourrich et al., 2012), they may provide another path through which DMT exerts neuroplastic effects.

5-methoxy- $N, \quad N$-dimethyltryptamine (5-MeO-DMT), a methoxylated derivative of DMT, is present endogenously in several species of plants, fungi, and the Sonoran Desert toad, bufo alvarius (Uthaug et al., 2019). It disrupts oscillatory neural activity in the PFC, the visual cortex (V1), and the mediodorsal nucleus of the thalamus (MD) in mice (Riga et al., 2014, 2018). Surprisingly, these effects are also observed in $5-\mathrm{HT}_{2 \mathrm{~A}} \mathrm{KO}$ mice, but not in $5-\mathrm{HT}_{2 \mathrm{~A}} \mathrm{KO}$ mice co-treated with WAY-100635, an antagonist of 5- $\mathrm{HT}_{1 \mathrm{~A}}$ (Riga et al., 2018). It has been speculated that 5-MeO-DMT's action may depend on brain states: in anesthetized animals, it preferentially targets $5-\mathrm{HT}_{1 \mathrm{~A}}$ receptors on GABAergic inhibitory interneurons, whereas in awake animals it primarily binds to $5-\mathrm{HT}_{1 \mathrm{~A}}$ receptors on excitatory pyramidal neurons. Such state-dependent actions would differentially affect excitation/inhibition balance in the brain and may explain the opposite effect of 5-MeO-DMT on anesthetized vs. awake $5-\mathrm{HT}_{2 \mathrm{~A}} \mathrm{KO}$ mice (Riga et al., 2018). Intracerebroventricular administration of 5-MeO-DMT increases the proliferation of neural progenitors and these newborn neurons possess more complex dendritic arbors and exhibit shorter afterhyperpolarization potentials as well as higher action potential thresholds compared to saline-treated controls (Lima da Cruz et al., 2018). Moreover, a mass spectrometry analysis of human cerebral organoids treated with 5-MeO-DMT reveals its modulatory effects on proteins involved in long-term potentiation, dendritic spine formation, microtubule dynamics, and cytoskeletal organization, highlighting the potential impact of 5-MeO-DMT on neuroplasticity (Dakic et al., 2017).

\section{Ibogaine and Its Analog}

Ibogaine is a psychoactive $\beta$-carboline derivative isolated from the root bark of the West African rainforest shrub Tabernanthe iboga (Dybowski and Landrin, 1901). It has a high affinity for several targets including the $N$-methyl- $D$-aspartate (NMDA), the $\kappa$ - and $\mu$-opioid, and the $5-\mathrm{HT}_{2 \mathrm{~A}}$ receptors. Furthermore, ibogaine has the highest affinity for the sigma-2 receptor among psychedelics (Baumann et al., 2001; Ray, 2010). In humans, ibogaine is metabolized by cytochrome P450 2D6 (CYP2D6) into noribogaine (10-hydroxyibogamine, also referred to as 12-hydroxyibogamine in the Chemical Abstracts Service nomenclature) (Obach et al., 1998). Noribogaine shows higher plasma levels and remains detectable for a much longer period than ibogaine, suggesting that it may be the active compound in vivo (Mash et al., 2000; Baumann et al., 2001). Indeed, recent research has suggested that it may be noribogaine, rather than ibogaine per se, that stimulates neuroplasticity. In cultured rat cortical neurons, noribogaine increases dendritic arbor complexity while ibogaine does not. Co-treatment with 
ketanserin blocks such effect of noribogaine, implicating 5$\mathrm{HT}_{2 \mathrm{~A}}$ receptor activation (Ly et al., 2018). Unfortunately, a high dosage of ibogaine $(\geq 50 \mathrm{mg} / \mathrm{kg}$ ) can be neurotoxic: it induces cerebellar Purkinje cell degeneration in rats, possibly due to excitotoxicity from the inferior olive (O'Hearn and Molliver, 1993, 1997; Xu et al., 2000). The small safety margin between the therapeutic dose $(40 \mathrm{mg} / \mathrm{kg}$ ) and the neurotoxic dose raises concerns about ibogaine's safety for clinical use (Baumann et al., 2001). To address ibogaine's hallucinogenic and toxicity problems, researchers conducted function-oriented synthesis to develop tabernanthalog (TBG), a non-hallucinogenic, noncardiotoxic analog of ibogaine (Cameron et al., 2021). TBG elevates the complexity of dendritic arbors of cultured rat cortical neurons and increases dendritic spine formation in the mouse somatosensory cortex in vivo. Such effects can be blocked by ketanserin co-treatment, indicating the involvement of $5-\mathrm{HT}_{2} \mathrm{~A}$ receptor signaling. A more recent study (Lu et al., 2021) showed that a single dose of TBG can rescue the elevated anxiety, cognitive inflexibility, and sensory processing deficits in mice subjected to unpredictable mild stress (UMS). It also partially compensates for the UMS-induced dendritic spine loss, restores the electrophysiological properties of parvalbumin-expressing inhibitory interneurons, and normalizes baseline and sensoryevoked cortical neuronal activities.

\section{Psilocybin}

Psilocybin is the active ingredient in so-called magic mushrooms (Geiger et al., 2018). In the body, psilocybin is quickly dephosphorylated into psilocin (Hasler et al., 1997), a compound that binds to several 5-HT receptor subtypes with relatively high affinity (Rickli et al., 2016). Both in vitro and in vivo studies on psilocybin have focused on its effect on excitatory synapses. They suggest that psilocybin promotes synaptic growth and strength. In cultured rat cortical neurons, psilocin increases dendritic arbor complexity and dendritic spine density (Ly et al., 2018). Likewise, a single dose of psilocybin promotes the formation of dendritic spines on layer 5 pyramidal neurons in the mouse medial frontal cortex in vivo, significantly increasing spine density; the psilocybin-induced new spines are no less stable than those formed under control conditions. In addition, psilocybin increases spine head size, which represents a strengthening of synapses (Shao et al., 2021). In the hippocampus and the PFC of pigs, a single dose of psilocybin also promotes synaptogenesis, as evidenced by a persistent increase in the presynaptic density of synaptic vesicle protein 2 (SV2A), a presynaptic integral glycoprotein that regulates neurotransmitter release (Raval et al., 2021). Another recent study (Hesselgrave et al., 2021) also shows that psilocybin increases synaptic strength, measured as an increased AMPA/NMDA ratio at the synapses between temporoammonic inputs and the distal dendrites of hippocampal CA1 pyramidal neurons in mice.

\section{LSD}

LSD is an ergoline first synthesized by Albert Hofmann in 1938 from the lysergic acid found in ergot, a fungus that grows on grains (Hofmann, 1979). Despite the long-standing interest in LSD's cognitive effects, its cellular impact has only been explored recently. On the neural circuit level, LSD can modulate the spontaneous firing and burst-firing of reticular thalamus GABAergic neurons and disinhibit thalamocortical relay neurons in the mediodorsal thalamus in mice, as shown by in vivo electrophysiology (Inserra et al., 2021b). At the sub-cellular level, one study (Ly et al., 2018) on cultured rat cortical neurons found that $24 \mathrm{~h}$ LSD treatment significantly increases dendritic arbor complexity and dendritic spine density. There is a concurrent increase in synaptic density as measured by the co-localization of the presynaptic marker VGLUT1 and the postsynaptic marker PSD95. Although LSD binds to several 5-HT receptors with high affinity, its neuroplastic effects require $5-\mathrm{HT}_{2 \mathrm{~A}}$ receptor activation, as they are abrogated by co-treatment with ketanserin. Subsequently, it was shown (Ly et al., 2021) that shorter periods (15 min-6h) of LSD stimulation already suffice to increase dendritic arbor complexity and spine density.

\section{DOI}

Phenethylamines are probably the most extensively explored class of psychedelics due to their ease of synthesis (Nichols, 2018). Paradoxically, we know relatively little about the neuroplastic effects of most phenethylamines except DOI, which was first synthesized in 1973 (Coutts and Malicky, 1973). In cultured neurons, transient $(1 \mathrm{~h})$ DOI treatment increases dendritic spine size (Jones et al., 2009), and longer treatment increases the morphological dynamics of dendritic growth cones and neurite complexity, length, and number (Persico et al., 2006; Ohtani et al., 2014; Ly et al., 2018). In the mouse frontal cortex, DOI treatment selectively elevates the density of stubby and thin spines, but not of mature mushroom spines, on layer $2 / 3$ pyramidal neurons; it also enhances long-term potentiation (LTP) at synapses onto such neurons (de la Fuente Revenga et al., 2021). In vivo studies further show that DOI promotes dendritic spine formation in the mouse sensory cortex without affecting spine elimination (Cameron et al., 2021).

DOI can also perturb cellular and network activity in the cortex. Extracellular recordings in the rat frontal cortex show that DOI reduces low-frequency oscillations and disrupts the temporal relationship between pyramidal neuron discharges and the local field potential (LFP). Both effects can be blocked by the $5-\mathrm{HT}_{2 \mathrm{~A}}$ antagonist M100907, implicating 5- $\mathrm{HT}_{2 \mathrm{~A}}$ activation (Celada et al., 2008). In the primary visual cortex of awake mice, DOI reduces visually-evoked responses and surround suppression but spares basic retinotopic organization, tuning properties, and receptive field structure, which supports the idea that reduced bottom-up sensory drive underlies psychedelicinduced hallucinations (Michaiel et al., 2019).

The neuritogenesis- and synaptogenesis-promoting effects of DOI are blocked in culture when co-treated with ANA-12, ketanserin, or rapamycin, implicating signaling from TrkB, 5$\mathrm{HT}_{2 \mathrm{~A}}$, and mTOR, respectively, in DOI's downstream effects (Ly et al., 2018). Moreover, a single administration of DOI in $5-\mathrm{HT}_{2 \mathrm{~A}}$ knock-out mice does not increase the density of new synaptic spines in the frontal cortex, further suggesting that $5-\mathrm{HT}_{2 \mathrm{~A}}$ activation is critical for DOI induced neuroplasticity (de La Fuente Revenga et al., 2021). DOI's effects also depend on kalirin-7, a guanine nucleotide exchange factor that is a 
major regulator of dendritic spine morphogenesis in pyramidal neurons (Penzes and Jones, 2008), as incubating cultured cortical neurons in kalirin-7 interfering peptides, peptides that displace kalirin-7 from the postsynaptic density of dendritic spines, also blocks DOI's neuroplastic effects (Jones et al., 2009). However, there is evidence that a single administration of DOI in mice induces epigenetic changes in enhancer regions, regions of DNA that increase the likelihood that certain genes will be transcribed, that persist for at least a week after DOI administration, suggesting a molecular basis for long-term effects (de La Fuente Revenga et al., 2021).

\section{Ketamine}

First synthesized in 1965 (McCarthy et al., 1965), ketamine is not a serotonergic psychedelic, but a non-competitive $N$-methyl$\mathrm{D}$-aspartate receptor (NMDAR) antagonist initially used as a general anesthetic. Notably, ketamine also produces significant psychological effects including hallucinations and dissociation from reality, not unlike the behavioral effects of psychedelics. Moreover, recent studies have highlighted its antidepressant effect (Nowacka and Borczyk, 2019). It is thus interesting to discuss ketamine's effects together with those of psychedelics.

Like classical psychedelics, ketamine also promotes neuroplasticity. Cultured rat cortical neurons significantly increase spinogenesis and synaptogenesis after $15 \mathrm{~min}$ of ketamine treatment (Ly et al., 2021). Similarly, transient ketamine treatment promotes the dendritic arborization of dopaminergic neurons either cultured from embryonic mouse mesencephalon or derived from human induced pluripotent stem cells (iPSCs) (Cavalleri et al., 2018). An enhancement in structural plasticity is also reported by multiple animal studies. For example, ketamine rapidly increases the spine density of L5 pyramidal neurons in the medial prefrontal cortex (mPFC) of rats (Li et al., 2010) as well as in hippocampal CA1 neurons in Flinders Sensitive Line (FSL) rats, a genetic model of depression (Treccani et al., 2019); it also significantly ameliorates the spine density decrease in the $\mathrm{mPFC}$ and hippocampus of mice subjected to chronic social defeat stress (Zhang et al., 2019). In vivo imaging studies further show that ketamine enhances spine formation in the mouse medial frontal cortex (Phoumthipphavong et al., 2016) and somatosensory cortex (Pryazhnikov et al., 2018), and partially restores spines lost during chronic exposure to corticosterone (Moda-Sava et al., 2019). Such plasticity is believed to underlie ketamine's rescuing effect on depression-like behaviors in rodent models (Moda-Sava et al., 2019). In addition to the structural plasticity, ketamine can elicit a form of functional synaptic plasticity reminiscent of homeostatic synaptic upscaling, providing another possible cellular mechanism for its antidepressant effect (Kavalali and Monteggia, 2020).

\section{CONCLUSION AND DISCUSSION}

Since the early 20th century, there has been considerable interest in using psychedelics to treat mental illnesses (CarhartHarris and Goodwin, 2017; Bogenschutz and Ross, 2018; Nichols and Walter, 2021). Numerous clinical studies have shown encouraging therapeutic potentials of psychedelics, particularly LSD and psilocybin, and to a lesser extent ayahuasca, ibogaine, and dipropyltryptamine (DPT), in treating disorders including addiction to alcohol, nicotine, or illicit drugs, anorexia nervosa, depression, distress and anxiety concerning death, obsessive-compulsive disorder, and post-traumatic stress disorder (Bogenschutz and Johnson, 2016; Johnson et al., 2019; Dos Santos and Hallak, 2020; Foldi et al., 2020; Krediet et al., 2020; Andersen et al., 2021; Dos Santos et al., 2021). The neuroplastic effects of psychedelics, however, have only been appreciated much more recently. Given that DMT, LSD, and DOI, representatives of three classes of psychedelics, as well as ketamine, all possess the ability to promote dendritic branching and dendritic spine formation, it is conceivable that the therapeutic effects of psychedelics are at least partially mediated through the reconfiguration of neuronal networks. The formation of new dendritic spines represents the addition of new synapses to the neuronal circuitry (Knott et al., 2006). The new synaptic connections will persist or be eliminated in an activity-dependent manner; their presence or disappearance will in turn shape the activity patterns of the neurons they reside on ( $\mathrm{Fu}$ and $\mathrm{Zuo}, 2011)$. In addition, psychedelics may modulate dendritic excitability in a compartmentalized manner through interactions with 5-HT receptor subtypes that are coexpressed in the same neuron but with distinct subcellular localizations. The local control of membrane excitability will affect dendritic calcium signaling and, consequently, synaptic plasticity and alter synaptic integration (Savalia et al., 2021). Through such reciprocal structural and functional modifications, some new synapses may eventually outcompete the existing aberrant synapses, and the neuronal circuit may cease the abnormal firing that underlies mental illnesses. The physical change in neural circuit connectivity potentially explains the persistence of symptomatic improvements.

Psychedelics' molecular mechanisms of action are very complex (Nichols, 2016). While 5- $\mathrm{HT}_{2 \mathrm{~A}} \mathrm{R}$ signaling is widely believed to be a major contributor to psychedelics' effects, some recent studies indicate that it is not the sole player. One study shows that ketanserin treatment does not abolish the antidepressant effect of psilocybin in mice (Hesselgrave et al., 2021); another suggests that psilocybin decreases 5$\mathrm{HT}_{2 \mathrm{~A}} \mathrm{R}$ density in the hippocampus and PFC of pigs while increasing synaptic density (Raval et al., 2021). Indeed, in addition to being agonists or partial agonists of the $5-\mathrm{HT}_{2 \mathrm{~A}} \mathrm{R}$, all known psychedelics are also agonists of the $5-\mathrm{HT}_{2 \mathrm{C}} \mathrm{R}$. The $5-\mathrm{HT}_{1 \mathrm{~A}} \mathrm{R}$ is also likely involved, particularly for tryptamines and LSD (Nichols, 2004, 2016). Moreover, psychedelics may have an affinity for other receptors. For example, LSD is a high-affinity agonist of dopaminergic receptors (Watts et al., 1995). In fact, a screening of 35 psychedelics at 51 receptors, transporters, and ion channels suggests that the interaction profile of psychedelics is broader than generally believed (Ray, 2010). Intracellularly, accumulating evidence suggests a central role of $\operatorname{TrkB} / \mathrm{BDNF}$ (brain-derived neurotrophic factor) and mTOR signaling pathways in the neuroplastic and behavioral effects of psychedelics (Ly et al., 2018, 2021; De Gregorio et al., 2021; Inserra et al., 2021a). Interestingly, although ketamine 
binds to a completely different receptor (NMDAR), its prosynaptogenesis and antidepressant effects also engage BDNF and mTOR signaling (Li et al., 2010; Autry et al., 2011; Liu et al., 2012; Zanos and Gould, 2018; Aguilar-Valles et al., 2021). Such convergence in intracellular signaling not only provides a molecular mechanism for the shared cellular and behavioral phenotypes of ketamine and psychedelic treatment, but also hints at the molecular etiology of the psychiatric abnormalities they both ameliorate. At the same time, future studies on the distinct signaling pathways engaged by these drugs (Zanos et al., 2016; Marinova et al., 2017; Wu et al., 2021) will help resolve the difference in their duration of effect (Hibicke et al., 2020) and other pharmacological characteristics.

Many questions regarding the neuroplastic effects of psychedelics remain to be addressed. Are the dendritic spine dynamics localized to certain hotspots on the dendrite, specific to particular inputs, or uniformly distributed across the dendritic arbor? What are the functional implications of the observed structural plasticity? For example, are induced new synapses stronger and more active? Do different types of psychedelics, with their complex pharmacology, induce neuroplasticity with different spatiotemporal patterns in specific

\section{REFERENCES}

Aguilar-Valles, A., De Gregorio, D., Matta-Camacho, E., Eslamizade, M. J., Khlaifia, A., Skaleka, A., et al. (2021). Antidepressant actions of ketamine engage cell-specific translation via eIF4E. Nature 590, 315-319. doi: 10.1038/s41586-020-03047-0

Andersen, K. A. A., Carhart-Harris, R., Nutt, D. J., and Erritzoe, D. (2021). Therapeutic effects of classic serotonergic psychedelics: a systematic review of modern-era clinical studies. Acta Psychiatr. Scand. 143, 101-118. doi: 10.1111/acps.13249

Autry, A. E., Adachi, M., Nosyreva, E., Na, E. S., Los, M. F., Cheng, P. F., et al. (2011). NMDA receptor blockade at rest triggers rapid behavioural antidepressant responses. Nature 475, 91-95. doi: 10.1038/nature 10130

Baumann, M. H., Pablo, J., Ali, S. F., Rothman, R. B., and Mash, D. C. (2001). Comparative neuropharmacology of ibogaine and its Odesmethyl metabolite, noribogaine. Alkaloids Chem. Biol. 56, 79-113. doi: 10.1016/S0099-9598(01)56009-5

Berger, M., Gray, J. A., and Roth, B. L. (2009). The expanded biology of serotonin. Annu. Rev. Med. 60, 355-366. doi: 10.1146/annurev.med.60.042307.110802

Bogenschutz, M. P., and Johnson, M. W. (2016). Classic hallucinogens in the treatment of addictions. Prog. Neuropsychopharmacol. Biol. Psychiatry 64, 250-258. doi: 10.1016/j.pnpbp.2015.03.002

Bogenschutz, M. P., and Ross, S. (2018). Therapeutic applications of classic hallucinogens. Curr. Top. Behav. Neurosci. 36, 361-391. doi: 10.1007/7854_2016_464

Cameron, L. P., Benson, C. J., Defelice, B. C., Fiehn, O., and Olson, D. E. (2019). Chronic, intermittent microdoses of the psychedelic N,N-Dimethyltryptamine (DMT) produce positive effects on mood and anxiety in rodents. ACS Chem. Neurosci. 10, 3261-3270. doi: 10.1021/acschemneuro.8b00692

Cameron, L. P., Tombari, R. J., Lu, J., Pell, A. J., Hurley, Z. Q., Ehinger, Y., et al. (2021). A non-hallucinogenic psychedelic analogue with therapeutic potential. Nature 589, 474-479. doi: 10.1038/s41586-020-3008-z

Carhart-Harris, R. L., and Goodwin, G. M. (2017). The therapeutic potential of psychedelic drugs: past, present, and future. Neuropsychopharmacology 42, 2105-2113. doi: 10.1038/npp.2017.84

Cavalleri, L., Merlo Pich, E., Millan, M. J., Chiamulera, C., Kunath, T., Spano, P. F., et al. (2018). Ketamine enhances structural plasticity in mouse mesencephalic types of neurons? Moreover, it is important to clarify the molecular and circuit underpinnings of the differential effects generated by psychedelics and their analogs. Finally, how do the hallucinogenic and neuroplastic effects interact and contribute to the therapeutic potential of psychedelics? To address these questions, a cross-disciplinary collaboration is needed among chemists, molecular/cell biologists, synaptic physiologists, and clinical neuroscientists.

\section{AUTHOR CONTRIBUTIONS}

KL, JB, YZ, and JL: wrote the manuscript. All authors contributed to the article and approved the submitted version.

\section{FUNDING}

This work was supported by grants from the National Institute of Mental Health (R01MH109475), the National Institute of Child Health and Human Development (R21HD101266), the National Institute on Aging (R01AG071787), and a Max Planck Fellowship at the Max Planck Florida Institute for Neuroscience to YZ. and human iPSC-derived dopaminergic neurons via AMPAR-driven BDNF and mTOR signaling. Mol. Psychiatry 23, 812-823. doi: 10.1038/mp.2017.241

Celada, P., Puig, M. V., Diaz-Mataix, L., and Artigas, F. (2008). The hallucinogen DOI reduces low-frequency oscillations in rat prefrontal cortex: reversal by antipsychotic drugs. Biol. Psychiatry 64, 392-400. doi: 10.1016/j.biopsych.2008.03.013

Coutts, R. T., and Malicky, J. L. (1973). The synthesis of some analogs of the hallucinogen 1-(2,5-Dimethoxy-4-methylphenyl)-2aminopropane (DOM). Can. J. Chem. 51, 1402-1409. doi: 10.1139/v 73-210

Cumming, P., Scheidegger, M., Dornbierer, D., Palner, M., Quednow, B. B., and Martin-Soelch, C. (2021). Molecular and functional imaging studies of psychedelic drug action in animals and humans. Molecules 26:2451. doi: 10.3390/molecules26092451

Dakic, V., Minardi Nascimento, J., Costa Sartore, R., Maciel, R. M., De Araujo, D. B., Ribeiro, S., et al. (2017). Short term changes in the proteome of human cerebral organoids induced by 5-MeO-DMT. Sci. Rep. 7:12863. doi: 10.1038/s41598-017-12779-5

De Gregorio, D., Aguilar-Valles, A., Preller, K. H., Heifets, B. D., Hibicke, M., Mitchell, J., et al. (2021). Hallucinogens in mental health: preclinical and clinical studies on LSD, psilocybin, MDMA, and ketamine. J. Neurosci. 41, 891-900. doi: 10.1523/JNEUROSCI.1659-20.2020

de La Fuente Revenga, M., Zhu, B., Guevara, C. A., Naler, L. B., Saunders, J. M., Zhou, Z., et al. (2021). Prolonged epigenetic and synaptic plasticity alterations following single exposure to a psychedelic in mice. bioRxiv [preprint]. doi: 10.1101/2021.02.24.432725

Dong, C., Ly, C., Dunlap, L. E., Vargas, M. V., Sun, J., Hwang, I. W., et al. (2021). Psychedelic-inspired drug discovery using an engineered biosensor. Cell 184, 2779-2792.e2718. doi: 10.1016/j.cell.2021. 03.043

Dos Santos, R. G., Hallak, J. E., Baker, G., and Dursun, S. (2021). Hallucinogenic/psychedelic 5HT2A receptor agonists as rapid antidepressant therapeutics: Evidence and mechanisms of action. J. Psychopharmacol. 35, 453-458. doi: 10.1177/0269881120986422

Dos Santos, R. G., and Hallak, J. E. C. (2020). Therapeutic use of serotoninergic hallucinogens: a review of the evidence and of the biological and psychological mechanisms. Neurosci. Biobehav. Rev. 108, 423-434 doi: 10.1016/j.neubiorev.2019.12.001 
Dybowski, J., and Landrin, E. (1901). Sur l'Iboga, sur ses propriétés excitantes, sa composition, et sur l'alcaloïde nouveau qu'il renferme, l'ibogaïne. C. R. Hebd. Seances Acad. Sci. 133, 748-750.

Foldi, C. J., Liknaitzky, P., Williams, M., and Oldfield, B. J. (2020). Rethinking therapeutic strategies for anorexia nervosa: insights from psychedelic medicine and animal models. Front. Neurosci. 14:43. doi: 10.3389/fnins.2020.00043

Fontanilla, D., Johannessen, M., Hajipour, A. R., Cozzi, N. V., Jackson, M. B., and Ruoho, A. E. (2009). The hallucinogen N,N-dimethyltryptamine (DMT) is an endogenous sigma-1 receptor regulator. Science 323, 934-937. doi: 10.1126/science.1166127

Forrest, M. P., Parnell, E., and Penzes, P. (2018). Dendritic structural plasticity and neuropsychiatric disease. Nat. Rev. Neurosci. 19, 215-234. doi: $10.1038 / \mathrm{nrn} .2018 .16$

$\mathrm{Fu}, \mathrm{M}$., and Zuo, Y. (2011). Experience-dependent structural plasticity in the cortex. Trends Neurosci. 34, 177-187. doi: 10.1016/j.tins.2011.02.001

Geiger, H. A., Wurst, M. G., and Daniels, R. N. (2018). DARK classics in chemical neuroscience: psilocybin. ACS Chem. Neurosci. 9, 2438-2447. doi: 10.1021/acschemneuro.8b00186

Gerard, R. W. (1956). Neuropharmacology: Transactions of the Second Conference. New York, NY: Josiah Macy, Jr. Foundation.

Glennon, R. A., Titeler, M., and Mckenney, J. D. (1984). Evidence for 5-HT2 involvement in the mechanism of action of hallucinogenic agents. Life Sci. 35, 2505-2511. doi: 10.1016/0024-3205(84)90436-3

Gonzalez-Maeso, J., Weisstaub, N. V., Zhou, M., Chan, P., Ivic, L., Ang, R., et al. (2007). Hallucinogens recruit specific cortical 5-HT(2A) receptormediated signaling pathways to affect behavior. Neuron 53, 439-452. doi: 10.1016/j.neuron.2007.01.008

Goto, Y., Yang, C. R., and Otani, S. (2010). Functional and dysfunctional synaptic plasticity in prefrontal cortex: roles in psychiatric disorders. Biol. Psychiatry 67, 199-207. doi: 10.1016/j.biopsych.2009.08.026

Hasler, F., Bourquin, D., Brenneisen, R., Bar, T., and Vollenweider, F. X. (1997). Determination of psilocin and 4-hydroxyindole-3-acetic acid in plasma by HPLC-ECD and pharmacokinetic profiles of oral and intravenous psilocybin in man. Pharm. Acta Helv. 72, 175-184. doi: 10.1016/S0031-6865(97)00014-9

Heffter, A. (1894). Ueber Pellote. Ein Beitrag zur pharmakologischen Kenntniss der Cacteen. Archiv. f. experiment. Pathol. u. Pharmakol. 34, 65-86. doi: 10.1007/BF01864855

Hesselgrave, N., Troppoli, T. A., Wulff, A. B., Cole, A. B., and Thompson, S. M. (2021). Harnessing psilocybin: antidepressant-like behavioral and synaptic actions of psilocybin are independent of 5-HT2R activation in mice. Proc. Natl. Acad. Sci. U. S. A. 118:e2022489118. doi: 10.1073/pnas.2022489118

Hibicke, M., Landry, A. N., Kramer, H. M., Talman, Z. K., and Nichols, C. D. (2020). Psychedelics, but not ketamine, produce persistent antidepressant-like effects in a rodent experimental system for the study of depression. ACS Chem. Neurosci. 11, 864-871. doi: 10.1021/acschemneuro.9b00493

Hofmann, A. (1979). How LSD originated. J. Psychedelic Drugs 11, 53-60. doi: 10.1080/02791072.1979.10472092

Hofmann, A., Heim, R., Brack, A., and Kobel, H. (1958). Psilocybin, ein psychotroper Wirkstoff aus dem mexikanischen Rauschpilz Psilocybe mexicana Heim. Experientia 14, 107-109. doi: 10.1007/BF02159243

Holtmaat, A., and Svoboda, K. (2009). Experience-dependent structural synaptic plasticity in the mammalian brain. Nat. Rev. Neurosci. 10, 647-658. doi: $10.1038 / \mathrm{nrn} 2699$

Huxley, A., and Osmond, H. (2018). Psychedelic Prophets: The Letters of Aldous Huxley and Humphry Osmond. Montreal, QC: McGill-Queen's University Press. doi: $10.2307 / j . c t v 7 \mathrm{r} 40 \mathrm{jc}$

Inserra, A., De Gregorio, D., and Gobbi, G. (2021a). Psychedelics in psychiatry: neuroplastic, immunomodulatory, and neurotransmitter mechanisms. Pharmacol. Rev. 73, 202-277. doi: 10.1124/pharmrev.120.000056

Inserra, A., De Gregorio, D., Rezai, T., Lopez-Canul, M. G., Comai, S., and Gobbi, G. (2021b). Lysergic acid diethylamide differentially modulates the reticular thalamus, mediodorsal thalamus, and infralimbic prefrontal cortex: An in vivo electrophysiology study in male mice. J. Psychopharmacol. 35, 469-482. doi: $10.1177 / 0269881121991569$

Johnson, M. W., Hendricks, P. S., Barrett, F. S., and Griffiths, R. R. (2019). Classic psychedelics: an integrative review of epidemiology, therapeutics, mystical experience, and brain network function. Pharmacol. Ther. 197, 83-102. doi: 10.1016/j.pharmthera.2018.11.010
Jones, K. A., Srivastava, D. P., Allen, J. A., Strachan, R. T., Roth, B. L., and Penzes, P. (2009). Rapid modulation of spine morphology by the 5-HT2A serotonin receptor through kalirin-7 signaling. Proc. Natl. Acad. Sci. U. S. A. 106, 19575-19580. doi: 10.1073/pnas.0905884106

Kadriu, B., Greenwald, M., Henter, I. D., Gilbert, J. R., Kraus, C., Park, L. T., et al. (2021). Ketamine and serotonergic psychedelics: common mechanisms underlying the effects of rapid-acting antidepressants. Int. J. Neuropsychopharmacol. 24, 8-21. doi: 10.1093/ijnp/pyaa087

Kavalali, E. T., and Monteggia, L. M. (2020). Targeting homeostatic synaptic plasticity for treatment of mood disorders. Neuron 106, 715-726. doi: 10.1016/j.neuron.2020.05.015

Knott, G. W., Holtmaat, A., Wilbrecht, L., Welker, E., and Svoboda, K. (2006). Spine growth precedes synapse formation in the adult neocortex in vivo. Nat. Neurosci. 9, 1117-1124. doi: 10.1038/nn1747

Kourrich, S., Su, T. P., Fujimoto, M., and Bonci, A. (2012). The sigma-1 receptor: roles in neuronal plasticity and disease. Trends Neurosci. 35, 762-771. doi: 10.1016/j.tins.2012.09.007

Krediet, E., Bostoen, T., Breeksema, J., Van Schagen, A., Passie, T., and Vermetten, E. (2020). Reviewing the potential of psychedelics for the treatment of PTSD. Int. J. Neuropsychopharmacol. 23, 385-400. doi: 10.1093/ijnp/pyaa018

Li, N., Lee, B., Liu, R. J., Banasr, M., Dwyer, J. M., Iwata, M., et al. (2010). mTOR-dependent synapse formation underlies the rapid antidepressant effects of NMDA antagonists. Science 329, 959-964. doi: 10.1126/science.1190287

Lima da Cruz, R. V., Moulin, T. C., Petiz, L. L., and Leao, R. N. (2018). A single dose of 5-MeO-DMT stimulates cell proliferation, neuronal survivability, morphological and functional changes in adult mice ventral dentate gyrus. Front. Mol. Neurosci. 11:312. doi: 10.3389/fnmol.2018.00312

Liu, R. J., Lee, F. S., Li, X. Y., Bambico, F., Duman, R. S., and Aghajanian, G. K. (2012). Brain-derived neurotrophic factor Val66Met allele impairs basal and ketamine-stimulated synaptogenesis in prefrontal cortex. Biol. Psychiatry 71, 996-1005. doi: 10.1016/j.biopsych.2011.09.030

Lopez-Gimenez, J. F., and Gonzalez-Maeso, J. (2018). Hallucinogens and serotonin 5-HT2A receptor-mediated signaling pathways. Curr. Top. Behav. Neurosci. 36, 45-73. doi: 10.1007/7854_2017_478

Lu, J., Tjia, M., Mullen, B., Cao, B., Lukasiewicz, K., Shah-Morales, S., et al. (2021). An analog of psychedelics restores functional neural circuits disrupted by unpredictable stress. Mol. Psychiatry. doi: 10.1038/s41380-021-01159-1. [Epub ahead of print].

Ly, C., Greb, A. C., Cameron, L. P., Wong, J. M., Barragan, E. V., Wilson, P. C., et al. (2018). Psychedelics promote structural and functional neural plasticity. Cell Rep. 23, 3170-3182. doi: 10.1016/j.celrep.2018.05.022

Ly, C., Greb, A. C., Vargas, M. V., Duim, W. C., Grodzki, A. C. G., Lein, P. J., et al. (2021). Transient stimulation with psychoplastogens is sufficient to initiate neuronal growth. ACS Pharmacol. Transl. Sci. 4, 452-460. doi: 10.1021 /acsptsci.0c00065

Madsen, M. K., Fisher, P. M., Burmester, D., Dyssegaard, A., Stenbaek, D. S., Kristiansen, S., et al. (2019). Psychedelic effects of psilocybin correlate with serotonin $2 \mathrm{~A}$ receptor occupancy and plasma psilocin levels. Neuropsychopharmacology 44, 1328-1334. doi: 10.1038/s41386-0190324-9

Marinova, Z., Walitza, S., and Grünblatt, E. (2017). The hallucinogen 2,5dimethoxy-4-iodoamphetamine hydrochloride activates neurotrophin receptors in a neuronal cell line and promotes neurites extension. J. Neural Transm. (Vienna) 124, 749-759. doi: 10.1007/s00702-017-1706-y

Mash, D. C., Kovera, C. A., Pablo, J., Tyndale, R. F., Ervin, F. D., Williams, I. C., et al. (2000). Ibogaine: complex pharmacokinetics, concerns for safety, and preliminary efficacy measures. Ann. N. Y. Acad. Sci. 914, 394-401. doi: 10.1111/j.1749-6632.2000.tb05213.x

McCarthy, D. A., Chen, G., Kaump, D. H., and Ensor, C. (1965). General anesthetic and other pharmacological properties of 2-(O-Chlorophenyl)2-methylamino cyclohexanone $\mathrm{Hcl}$ (Ci-581). J New Drugs 5, 21-33. doi: 10.1002/j.1552-4604.1965.tb00219.x

Michaiel, A. M., Parker, P. R. L., and Niell, C. M. (2019). A hallucinogenic serotonin-2A receptor agonist reduces visual response gain and alters temporal dynamics in mouse V1. Cell Rep. 26, 3475-3483.e3474. doi: 10.1016/j.celrep.2019.02.104

Moda-Sava, R. N., Murdock, M. H., Parekh, P. K., Fetcho, R. N., Huang, B. S., Huynh, T. N., et al. (2019). Sustained rescue of prefrontal circuit 
dysfunction by antidepressant-induced spine formation. Science 364:eaat8078. doi: $10.1126 /$ science.aat 8078

Nichols, D., Yensen, R., and Metzner, R. (1993). The great entactogen empathogen debate. Newsl. Multidiscipl. Assoc. Psychedelic Stud. 4, 47-49.

Nichols, D. E. (1986). Differences between the mechanism of action of MDMA, MBDB, and the classic hallucinogens. Identification of a new therapeutic class: entactogens. J. Psychoactive Drugs 18, 305-313. doi: 10.1080/02791072.1986.10472362

Nichols, D. E. (2004). Hallucinogens. Pharmacol. Ther. 101, 131-181. doi: 10.1016/j.pharmthera.2003.11.002

Nichols, D. E. (2016). Psychedelics. Pharmacol. Rev. 68, 264-355. doi: 10.1124/pr.115.011478

Nichols, D. E. (2018). Chemistry and structure-activity relationships of psychedelics. Curr. Top. Behav. Neurosci. 36, 1-43. doi: 10.1007/7854_2017_475

Nichols, D. E., and Walter, H. (2021). The history of psychedelics in psychiatry. Pharmacopsychiatry 54, 151-166. doi: 10.1055/a-1310-3990

Nowacka, A., and Borczyk, M. (2019). Ketamine applications beyond anesthesia - A literature review. Eur. J. Pharmacol. 860, 172547. doi: 10.1016/j.ejphar.2019.172547

Obach, R. S., Pablo, J., and Mash, D. C. (1998). Cytochrome P4502D6 catalyzes the O-demethylation of the psychoactive alkaloid ibogaine to 12hydroxyibogamine. Drug Metab. Dispos. 26, 764-768.

O'Hearn, E., and Molliver, M. E. (1993). Degeneration of Purkinje cells in parasagittal zones of the cerebellar vermis after treatment with ibogaine or harmaline. Neuroscience 55, 303-310. doi: 10.1016/0306-4522(93)90500-F

O'Hearn, E., and Molliver, M. E. (1997). The olivocerebellar projection mediates ibogaine-induced degeneration of Purkinje cells: a model of indirect, trans-synaptic excitotoxicity. J. Neurosci. 17, 8828-8841. doi: 10.1523/JNEUROSCI.17-22-08828.1997

Ohtani, A., Kozono, N., Senzaki, K., and Shiga, T. (2014). Serotonin 2A receptor regulates microtubule assembly and induces dynamics of dendritic growth cones in rat cortical neurons in vitro. Neurosci. Res. 81-82, 11-20. doi: 10.1016/j.neures.2014.03.006

Olson, D. E. (2018). Psychoplastogens: a promising class of plasticitypromoting neurotherapeutics. J. Exp. Neurosci. 12:1179069518800508. doi: $10.1177 / 1179069518800508$

Penzes, P., and Jones, K. A. (2008). Dendritic spine dynamics-a key role for kalirin-7. Trends Neurosci. 31, 419-427. doi: 10.1016/j.tins.2008.06.001

Persico, A. M., Di Pino, G., and Levitt, P. (2006). Multiple receptors mediate the trophic effects of serotonin on ventroposterior thalamic neurons in vitro. Brain Res. 1095, 17-25. doi: 10.1016/j.brainres.2006.04.006

Phoumthipphavong, V., Barthas, F., Hassett, S., and Kwan, A. C. (2016). Longitudinal effects of ketamine on dendritic architecture in vivo in the mouse medial frontal cortex. eNeuro 3:e0133-15.2016. doi: 10.1523/ENEURO.0133-15.2016

Pryazhnikov, E., Mugantseva, E., Casarotto, P., Kolikova, J., Fred, S. M., Toptunov, D., et al. (2018). Longitudinal two-photon imaging in somatosensory cortex of behaving mice reveals dendritic spine formation enhancement by subchronic administration of low-dose ketamine. Sci. Rep. 8:6464. doi: 10.1038/s41598-018-24933-8

Raval, N. R., Johansen, A., Donovan, L. L., Ros, N. F., Ozenne, B., Hansen, H. D., et al. (2021). A single dose of psilocybin increases synaptic density and decreases 5-HT2A receptor density in the pig brain. Int. J. Mol. Sci. 22:835. doi: $10.3390 /$ ijms 22020835

Ray, T. S. (2010). Psychedelics and the human receptorome. PLoS ONE 5:e9019. doi: 10.1371/annotation/e580a864-cf13-40c2-9bd9-b9687a6f0fe4

Rickli, A., Moning, O. D., Hoener, M. C., and Liechti, M. E. (2016). Receptor interaction profiles of novel psychoactive tryptamines compared with classic hallucinogens. Eur. Neuropsychopharmacol. 26, 1327-1337. doi: 10.1016/j.euroneuro.2016.05.001

Riga, M. S., Llado-Pelfort, L., Artigas, F., and Celada, P. (2018). The serotonin hallucinogen 5-MeO-DMT alters cortico-thalamic activity in freely moving mice: regionally-selective involvement of 5-HT1A and 5-HT2A receptors. Neuropharmacology 142, 219-230. doi: 10.1016/j.neuropharm.2017. 11.049

Riga, M. S., Soria, G., Tudela, R., Artigas, F., and Celada, P. (2014). The natural hallucinogen 5-MeO-DMT, component of ayahuasca, disrupts cortical function in rats: reversal by antipsychotic drugs. Int. J. Neuropsychopharmacol. 17, 1269-1282. doi: $10.1017 /$ S1461145714000261
Ruck, C. A., Bigwood, J., Staples, D., Ott, J., and Wasson, R. G. (1979). Entheogens. J. Psychedelic Drugs 11, 145-146. doi: 10.1080/02791072.1979.10472098

Rucker, J. J. H., Iliff, J., and Nutt, D. J. (2018). Psychiatry \& the psychedelic drugs. Past, present \& future. Neuropharmacology 142, 200-218. doi: 10.1016/j.neuropharm.2017.12.040

Saavedra, J. M., and Axelrod, J. (1972). Psychotomimetic N-methylated tryptamines: formation in brain in vivo and in vitro. Science 175, 1365-1366. doi: 10.1126/science.175.4028.1365

Savalia, N. K., Shao, L. X., and Kwan, A. C. (2021). A dendrite-focused framework for understanding the actions of ketamine and psychedelics. Trends Neurosci. 44, 260-275. doi: 10.1016/j.tins.2020.11.008

Shao, L. X., Liao, C., Gregg, I., Davoudian, P. A., Savalia, N. K., Delagarza, K., et al. (2021). Psilocybin induces rapid and persistent growth of dendritic spines in frontal cortex in vivo. Neuron 109, 2535-2544.e4. doi: 10.1016/j.neuron.2021.06.008

Treccani, G., Ardalan, M., Chen, F., Musazzi, L., Popoli, M., Wegener, G., et al. (2019). S-ketamine reverses hippocampal dendritic spine deficits in flinders sensitive line rats within $1 \mathrm{~h}$ of administration. Mol. Neurobiol. 56, 7368-7379. doi: 10.1007/s12035-019-1613-3

Uthaug, M. V., Lancelotta, R., Van Oorsouw, K., Kuypers, K. P. C., Mason, N., Rak, J., et al. (2019). A single inhalation of vapor from dried toad secretion containing 5-methoxy-N,N-dimethyltryptamine (5-MeODMT) in a naturalistic setting is related to sustained enhancement of satisfaction with life, mindfulness-related capacities, and a decrement of psychopathological symptoms. Psychopharmacology (Berl) 236, 2653-2666. doi: 10.1007/s00213-019-05236-w

Vollenweider, F. X., Vollenweider-Scherpenhuyzen, M. F., Babler, A., Vogel, H., and Hell, D. (1998). Psilocybin induces schizophrenia-like psychosis in humans via a serotonin-2 agonist action. Neuroreport 9, 3897-3902. doi: 10.1097/00001756-199812010-00024

Watts, V. J., Lawler, C. P., Fox, D. R., Neve, K. A., Nichols, D. E., and Mailman, R. B. (1995). LSD and structural analogs: pharmacological evaluation at D1 dopamine receptors. Psychopharmacology (Berl) 118, 401-409. doi: $10.1007 / \mathrm{BF} 02245940$

Wu, M., Minkowicz, S., Dumrongprechachan, V., Hamilton, P., and Kozorovitskiy, Y. (2021). Ketamine rapidly enhances glutamate-evoked dendritic spinogenesis in medial prefrontal cortex through dopaminergic mechanisms. Biol. Psychiatry 89, 1096-1105. doi: 10.1016/j.biopsych.2020.12.022

Xu, Z., Chang, L. W., Slikker, W. Jr., Ali, S. F., Rountree, R. L., and Scallet, A. C. (2000). A dose-response study of ibogaine-induced neuropathology in the rat cerebellum. Toxicol. Sci. 57, 95-101. doi: 10.1093/toxsci/57.1.95

Zanos, P., and Gould, T. D. (2018). Mechanisms of ketamine action as an antidepressant. Mol. Psychiatry 23, 801-811. doi: 10.1038/mp.2017.255

Zanos, P., Moaddel, R., Morris, P. J., Georgiou, P., Fischell, J., Elmer, G. I., et al. (2016). NMDAR inhibition-independent antidepressant actions of ketamine metabolites. Nature 533, 481-486. doi: 10.1038/nature17998

Zhang, J., Qu, Y., Chang, L., Pu, Y., and Hashimoto, K. (2019). (R)-Ketamine rapidly ameliorates the decreased spine density in the medial prefrontal cortex and hippocampus of susceptible mice after chronic social defeat stress. Int. J. Neuropsychopharmacol. 22, 675-679. doi: 10.1093/ijnp/pyz048

Conflict of Interest: The authors declare that the research was conducted in the absence of any commercial or financial relationships that could be construed as a potential conflict of interest.

Publisher's Note: All claims expressed in this article are solely those of the authors and do not necessarily represent those of their affiliated organizations, or those of the publisher, the editors and the reviewers. Any product that may be evaluated in this article, or claim that may be made by its manufacturer, is not guaranteed or endorsed by the publisher.

Copyright $\odot 2021$ Lukasiewicz, Baker, Zuo and Lu. This is an open-access article distributed under the terms of the Creative Commons Attribution License (CC BY). The use, distribution or reproduction in other forums is permitted, provided the original author(s) and the copyright owner(s) are credited and that the original publication in this journal is cited, in accordance with accepted academic practice. No use, distribution or reproduction is permitted which does not comply with these terms. 